\title{
Penerimaan Sistem Informasi Akuntansi Pada Pusat Kesehatan Masyarakat Yang Baru Menjadi Badan Layanan Umum Daerah (BLUD)
}

\author{
Rudy Suryanto, Mohamad Abdul Latif, Hafiez Sofyani* \\ Universitas Muhammadiyah Yogyakarta \\ *Penulis korespondensi, Surel: hafiez.sofyani@umy.ac.id
}

\begin{abstract}
$A B S T R A C T$
This study aims to analyze the acceptance of public service agency (BLUD) accounting information system at BLUD health center in Boyolali, Center Java. TAM model is used in this study with behavioral theory perspective that used to for examine information technology adopted process. The samples used in this research is accounting and financial staffs at BLUD health center in Java that using BLUD accounting information system that developed by PT. Syncore Indonesia. Data obtained from questionnaires distributed be procesed using partial least square $(P L S)$.The result of this research indicated 8 of 11 hipotheses are accepted. Where the result of this research showed relationship between users abilities and skills (UAS) toward percieved ease of use (PEOU), accounting information system (SIA) toward percieved usefulness (PU), percieved ease of use (PEOU) toward percieved usefulness (PU), percieved ease of use (PEOU) and percieved usefulness (PU) toward attitude toward using (ATU), percieved usefulness (PU) and attitude toward using (ATU) toward behavioral intention to use (BITU), and behavioral intention to use (BITU) toward actual system usage (ASU) are positif significant.
\end{abstract}

Keywords: Accounting Information System, Public Service Agency (BLUD), Structural Equation Model, Technology Acceptance Model (TAM)

\section{PENDAHULUAN}

Puskesmas memiliki kedudukan sebagai penyedia jasa kesehatan tingkat pertama yang bertanggung jawab menyelenggarakan Upaya Kesehatan Perorangan (UKP) dan Upaya Kesehatan Masyarakat (UKM). Sedangkan, Badan Layanan Umum Daerah (BLUD) yaitu suatu Satuan Kerja Perangkat Daerah (SKPD) di lingkungan Pemerintah Daerah yang dibentuk dengan tujuan untuk memberikan pelayanan kepada masyarakat berupa penyediaan barang atau jasa yang dijual tanpa mengutamakan mencari keuntungan saja dan dalam melakukan kegiatannya didasarkan pada prinsip efisiensi dan produktivitas (Surianto dan Trisnantoro, 2013). Menurut Indrayathi et al. (2014) alasan mengapa dibentuknya Puskesmas BLUD adalah karena banyaknya keluhan masyarakat akan rendahnya kualitas pelayanan di Puskesmas. Diharapkan dengan dibentuknya Puskesmas BLUD dapat meningkatkan kinerjanya, sehingga tanggung jawab sebagai penyedia jasa kesehatan tingkat pertama dapat dijalankan dengan baik.

Ada tiga syarat utama yang harus dipenuhi oleh suatu instansi agar dapat berstatus BLUD. Menurut Peraturan Pemerintah (PP) Nomor 23 Tahun 2005 pasal 4 tentang pengelolaan keuangan BLU menyebutkan suatu satuan kerja instansi pemerintah dapat diizinkan mengelola keuangan dengan PPK BLU apabila memenuhi persyaratan substantif, teknis, dan administratif. Syahril (2013) menjelaskan terkait persyaratan tersebut, dimana persyaratan substantif terkait dengan penyelenggaraan layanan umum, persyaratan teknis terkait dengan kinerja pelayanan dan kinerja keuangan, serta persyaratan administratif terkait dengan terpenuhinya

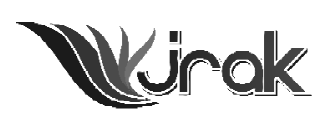

Jurnal Reviu Akuntansi dan Keuangan ISSN: 2088-0685 Vol.5 No. 1, April 2015 Pp 657-672 


\section{Penerimaan Sistem Informasi...}

658 dokumen seperti pola tata kelola, rencana strategis bisnis, standar layanan minimal, laporan keuangan pokok, dan laporan audit / bersedia untuk diaudit.

Namun demikian, dalam kenyataannya bahwa sebagian besar Puskesmas yang berstatus BLUD belum memiliki tenaga ahli keuangan yang memadai ${ }^{1}$. Oleh karena itu, puskesmas BLUD harus memiliki sistem pengelolaan keuangan yang mudah dipahami dan dioperasikan, serta mampu meningkatkan efektifitas dan efisiensi agar dapat terlaksana tujuan dari pemanfaat sistem itu sendiri, sesuai dengan Undang-undang Nomor 11 Tahun 2008 C tentang informasi dan transaksi elektronik (ITE) bahwa tujuan dari pemanfaatan teknologi adalah untuk meningkatkan efektivitas dan efisiensi pelayanan publik. Sehingga, dengan adanya sistem tersebut, nantinya akan membantu dan mempermudah tugas yang harus diemban oleh setiap staff pada suatu instansi walaupun mereka tidak begitu kompeten dibidang keuangan dan pelaporan keuangan.

Beberapa Puskesmas BLUD di Pulau Jawa telah menerapkan sistem informasi akuntansi (SIA) BLUD. Sistem ini merupakan sistem akuntansi dan keuangan yang dibuat oleh PT. Syncore Indonesia atas latar belakang permasalahan yang dipaparkan diatas.Diharapkan, dengan kehadiranSIA BLUD, maka BLUD mampu untuk mengatasi masalah-masalahnya terkait praktik pengelolaan keuangan, sehingga pengelolaan serta pelaporan keuangan pada suatu instansi BLUD pada umumnya dapat berjalan dengan baik dan sesuai dengan standar yang berlaku.

Akan tetapi, suatu teknologi informasi dapat dimanfaatkan secara efektif apabila penggunanya (users) memiliki kemampuan dan keahlian dalam menggunakan teknologi tersebut dengan baik (Mulyani, 2012). Hartono (2007) menjelaskan bahwa sistem teknologi informasi gagal diterapkan karena manusianya (pengguna) menolak atau tidak mau menggunakannya dengan banyak alasan. Begitu pula dengan sistem BLUD, sistem akan dapat berjalan dengan baik pemanfaatannya jika penggunanya memiliki kemampuan dan keahlian, sebaliknya sistem BLUD tidak akan dapat berjalan dengan baik jika penggunanya menolak atau tidak mau menggunakan. Oleh karena itu, untuk mengukur tingkat penerimaan pengguna sistem BLUD di beberapa Puskesmas BLUD, dapat dilakukan pendekatan menggunakan model penerimaan teknologi atau Technology Acceptance Model (TAM) yang dikembangkan oleh Davis (1986).

Penelitian mengenai TAM sendiri sejatinya sudah banyak dilakukan, misalnya lihat penelitian Davis (1989), Chin dan Todd (1995), Doll dan Torkzadeh (1998), Vijayasarathy (2004), Nah et al. (2004), Saadé dan Bahli (2005), Mulyani (2012), Hendrawati (2013), Devi dan Suartana (2014) dan Dalimunthe dan Wibisono (2014). Kebanyakan penelitian-penelitian terdahulu tersebut dilakukan di unit bisnis dan lembaga publik pemerintahan. Penelitian TAM yang dilakukan pada Pusat Kesehatan Masyarakat (Puskesmas) yang baru berubah status dari unit Satuan Kerja Perangkat Daerah (SKPD) menjad BLUDmasih sangat jarang dilakukan. Itulah kenapa pada penelitian ini obyek yang digunakan adalah BLUD. Model TAM pada penelitian sendiri ini merupakan replikasi dari penelitian yang dilakukan Mulyani (2012) yang meneliti mengenai penerimaan Stundent Information Terminal (S-IT) pada AMIK Garut.

\section{PENGEMBANGAN HIPOTESIS}

Desain sistem informasi akuntansi BLUD dalam penelitian ini berhubungan dengan desain tampilan dan kemampuan sistem yang jika didalam situs web meru-

Hasil laporan studi lapangan Syncore Consulting dan beberapa berita di media masa, salah satunya Cianjurekspres online. 2016. Puskesmas BLUD Minim Tenaga Ahli Keuangan. http://cianjurekspres.com/2016/puskesmas-blud-minim-tenaga-ahli-keuangan/. Diakses tanggal 15 Desember 2016 pukul 20.15 WIB.. 
pakan portal web, yang menggunakan menggunakan terminologi, navigasi, dan tampilan antarmuka sebagai indikator. Mulyani (2012) menjelaskan bahwa apabila desain portal dibuat dengan jelas, konsisten dan tidak membingungkan maka akan mempengaruhi para pemakai akan persepsi kemudahan penggunaan. Yuadi (2009) menjelaskan bahwa desain portal dirancang dengan baik supaya dapat membantu para pemakai dalam menggunakan sistem secara mudah dalam mengidentifikasi obyek tertentu pada layar atau penyediaan navigasi yang jelas. Jadi, jika sistem BLUD dirancang dengan baik dan sesuai dengan kebutuhan/selera/kemampuan para penggunanya, serta dapat diakses menggunakan berbagai perangkat, maka para pengguna sistem informasi tersebut akan memiliki persepsi bahwa sistem BLUD dapat dengan mudah digunakan. Sehingga, hipotesis pertama dalam penelitian ini adalah sebagai berikut:

$\mathrm{H}_{1}$ : Desain sistem informasi akuntansi BLUD berpengaruh positif terhadap percieved ease of use sistem BLUD.

Sistem informasi akuntansi dalam penelitian ini menggunakan indikator kualitas pengolahan data dan kualitas data yang dihasilkan oleh sistem BLUD. Mulyani (2012) menjelaskan bahwa dengan akses sistem yang mudah dan cepat serta sumber daya informasi yang baik maka akan memudahkan pengguna (user) dalam memperoleh informasi yang bervariasi.Sebuah sistem yang memiliki kualitas yang tinggi baik itu dari segi sistem secara keseluruhan, dari segi pengolahan data, ataupun dari data yang dihasilkan akan memberikan kemudahan serta manfaat bagi penggunanya. Sebelum para pengguna (user) menggunakan sistem BLUD secara aktual, pengguna (user) tersebut akan memiliki persepsi/berfikiran bahwa dengan kualitas sistem BLUD yang baik yang mampu mengolah informasi dengan baik, serta memiliki sumber daya informasi yang baik dan lengkap, maka akan memudahkan dan memberikan manfaat para pengguna (user) dalam menggunakannya. Sehingga, hipotesis dalam penelitian ini adalah:

$\mathrm{H}_{2}$ : Sistem informasi akuntansi berpengaruh positif terhadap percieved ease of use. $\mathrm{H}_{3}$ : Sistem informasi akuntansi berpengaruh positif terhadap percieved usefulness.

Users ability and skill atau kemampuan dan ketrampilan pengguna akan dapat sangat berpengaruh terhadap persepsi kemudahan penggunaan suatu sistem informasiDavis (1986). Dengan kemampuan dan ketrampilan yang dimiliki oleh seorang pengguna akan menimbulkan keyakinan diri (self efficacy) pada diri pengguna atas kemampuannya dalam menjalankan atau mengoperasikan sebuah perangkat sistem.Kemampuan dan ketrampilan pengguna yang baik akan meningkatkan keyakinan diri (self efficacy) dalam mengoperasikan atau menjalankan sebuah perangkat sistem (Doll dan Torkzadeh, 1998). Peningkatan keyakinan kemampuan dan ketrampilan diri ini akan menimbulkan persepsi pada diri pengguna bahwa sebuah sistem informasi mudah digunakan. Sehingga, hipotesis pada penelitian ini adalah:

$\mathrm{H}_{4}:$ Users ability and skills berpengaruh positif terhadap percieved ease of use.

Percieved ease of use (kemudahan penggunaan persepsian) berkaitan dengan kepercayaan atau indikasi seseorang apabila menggunakan suatu teknologi akan mengurangi beban pekerjaan penggunanya. Sedangkan percieved usefulness (kegunaan persepsian) didefinisikan sebagai sejauh mana seseorang percaya bahwa menggunakan suatu teknologi akan meningkatkan kinerjanya. Kemudian Davis (1986) mendefinisikan sikap terhadap menggunakan teknologi (attitude toward using) sebagai perasaan positif atau negatif dari seseorang jika harus menggunakan suatu teknologi.Seseorang akan mendapatkan perasaaan positif jika dalam penggunaannya terasa mudah dan cepat sehingga tercapai keefisienan kerja. Artinya, jika seseorang berfikiran bahwa suatu sistem mudah digunakan, maka pengguna tersebut bahwa sistem memiliki manfaat yaitu keefisienan kerja akan meningkat, 
Penerimaan
Sistem
Informasi...

660 selanjutnya pengguna tersebut akan bersikap untuk menggunakan sistem tersebut. Sehingga, hipotesis dalam penelitian ini adalah sebagai berikut:

$\mathrm{H}_{5}$ : Percieved ease of use berpengaruh positif terhadap percieved usefulness.

$\mathrm{H}_{6}:$ Percieved ease of use berpengaruh positif terhadap attitude toward using.

Menurut Hartono (2007) konstruk percieved usefulness merupakan konstruk yang paling banyak signifikan dan penting karena mempengaruhi konstruk lain. Dijelaskan sebelumnya bahwa sikap terhadap menggunakan teknologi (attitude toward using) didefinisikan sebagai perasaan positif atau negatif dari seseorang jika harus menggunakan suatu teknologi. Kemudian, Davis (1986) mendefinisikan behavioral intention to use sebagai minat (keinginan) seseorang untuk melakukan perilaku tertentu, dalam hal ini adalah menggunakan suatu sistem. Menurut Fatmawati (2015) pada fase minat (intention) disebut sebagai fase penerimaan, karena dengan minat yang dimiliki, pengguna akan menunjukkan sikap penerimaan terhadap penggunaan sistem informasi.

Nugroho (2012) menjelaskan bahwa dengan kelengakapan informasi yang dimiliki akan memberikan manfaat yang besar bagi pengguna, dan pengguna akan berfikir bahwa sistem tersebut meningkatkan efisiensi dan kenyamanan, sehingga pengguna akan bersikap positif terhadap perilaku penggunaan teknologi. Kemudian, jika seorang pengguna berfikir bahwa suatu sistem memiliki manfaat yang besar bagi dirinya, maka dia akan memiliki minat yang besar pula untuk menggunakan sistem tersebut guna mengurangi beban pekerjaan yang ditanggung. Artinya, jika suatu sistem dirasa mampu memberikan manfaat bagi penggunanya, maka sikap yang ditunjukan oleh penggunanya adalah positif. Selain itu pengguna sistem BLUD juga akan berminat untuk menggunakan sistem tersebut guna meningkatkan kinerjanya. Sehingga, hipotesis dalam penelitian ini adalah:

$\mathrm{H}_{7}$ : Percieved usefulness berpengaruh positif terhadap attitude toward using.

$\mathrm{H}_{8}$ : Percieved usefulness berpengaruh positif terhadap behavioral intention to use.

Dalam model TRA, ketiga konstruk ini merupakan konstruk yang berada pada sisi model minat perilaku. Dimana model minat perilaku ini terbentuk dari dua fungsi penentu yang berhubungan dengan faktor pribadi dan faktor sosial, keduanya membentuk dua konstruk variabel independen yaitu sikap terhadap perilaku (attitude toward behavior) dan norma subjektif (subjective norm), kemudian ditambah dengan satu variabel dependen yaitu minat perilaku, (Hartono, 2007).Sikap terhadap penggunaan (attitude toward using) merupakan sebuah evaluasi kepercayaan (belief) dan perasaan (affect) baik positif ataupun negatif yang dilakukan oleh individu dalam menggunakan suatu sistem, (Hartono, 2007). Hartono (2007) juga menjelaskan mengenai norma subjektif (subjective norm), dimana norma subjektif ini berhubungan dengan persepsi seseorang terhadap tekanan sosial yang akan mempengaruhi minat untuk melakukan atau tidak melakukan suatu perilaku. Dengan tingginya pengaruh yang diberikan pihak disekitar baik itu dorongan ataupun tekanan, akan membuat seorang individu akan melakukan suatu perilaku yang dipertimbangkan, dalam hal ini penggunaan sistem BLUD. Selain itu, ketika seorang pengguna sudah bersikap positif terhadap sistem BLUD yang digunakan, maka minat untuk menggunakan sistem tersebut juga akan semakin tinggi. Sehingga hipotesis dalam penelitian ini adalah:

$\mathrm{H}_{9}$ : Subjective norm berpengaruh positif terhadap behavioral intention to use. $\mathrm{H}_{10}$ : Attitude toward using berpengaruh positif terhadap behavioral intention to use.

Fatmawati (2015) menjelaskan bahwa minat dari pengguna untuk menggunakan sistem informasi diyakini akan mampu menggerakkan pengguna dalam 
menggunakan sistem informasi tersebut. Hal tersebut diperkuat dengan apa yang dijelaskan oleh Hartono (2007) bahwa seseorang akan melakukan sesuatu, jika dia memiliki minat untuk melakukannya. Lebih lanjut Hartono (2007) menjelaskan definisi perilaku dalam konteks penggunaan sistem informasi dan teknologi sebagai penggunaan sesungguhnya (actual use) dari teknologi.Menurut Fatmawati (2015) bahwa tingkat penggunaan sistem informasi pada pengguna dapat diprediksi dari sikap perhatiannya atau niat terhadap sistem informasi tersebut. Seseorang yang memiliki persepsi bahwa suatu sistem mudah digunakan dan bermanfaat akan memunculkan sikap positif terhadap sistem tersebut, kemudian hal tersebut akan memunculkan niat atau minat dari pengguna untuk menggunakan sistem tersebut. Dari niat tersebut akan semakin mendorong seseorang untuk menggunakan suatu sistem secara nyata agar manfaat dan kemudahan yang dipersepsikan dapat dirasakan. Sehingga, hipotesis pada penelitian ini adalah:

$\mathrm{H}_{11}$ : Behavioral intention to use berpengaruh positif terhadap actual system use.

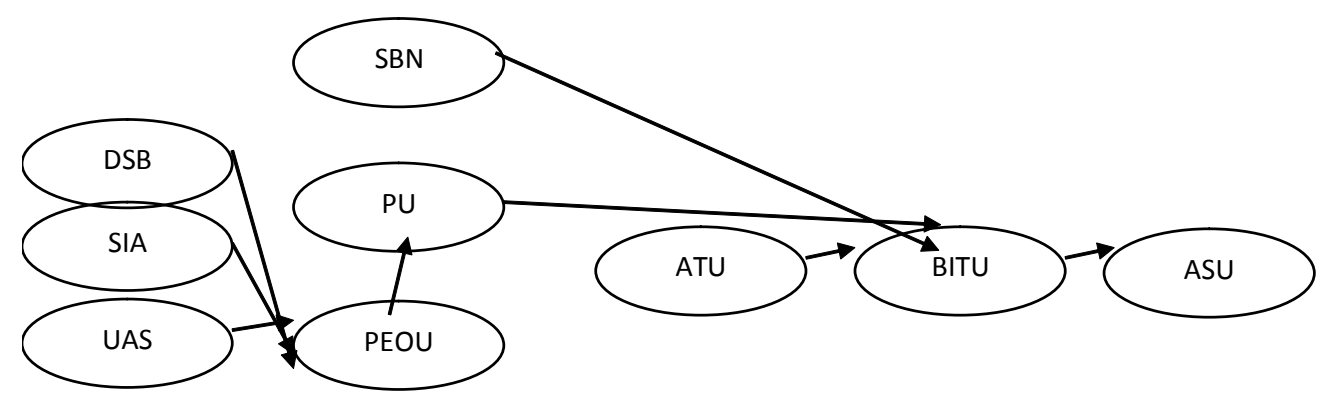

\section{Keterangan:}

DSB: Desain sistem BLUD

SIA : Sistem informasi akuntansi

UAS: Users abilities and skills

SBN: Subjective norms

ASU: Actual system using

\section{METODE PENELITIAN}

\section{Populasi dan sampel}

Populasi dalam penelitian ini adalah seluruh puskesmas yang ada di Boyolali. Sedangkan yang menjadi sampel dalam penelitian ini adalah Puskesmas yang sudah beralih status menjadi BLUD dan menggunakan SIA BLUD. Untuk mewakili sampel, dipilih responden penelitian dengan pendekatanpurposive sampling on respondent.Kriteria yang digunakan adalah responden harus merupakan Staff akuntansi atau keuangan Puskesmas yang telah berstatus BLUD dan menggunakan SIA BLUD dalam pengelolaan keuangannya. Kriteria ini dibuat agar responden sebagai perwakilan sampel yang digunakan dalam penelitian sesuai dengan tujuan penelitian ini sendiri.

\section{Metode Pengumpulan dan Pengukuran Data}

Teknik pengumpulan data yang digunakan dalam penelitian ini adalah menggunakan metode penyebaran dan pengambilan kuisioner secara langsung. Metode ini dipilih agar tingkat pengembalian kuesioner tinggi, mengingat respon masyarakat terhadap penelitian di Indonesia relative masih sangat rendah. Metode ini dinilai lebih efektif dan cocok dijalankan dibandingkan jika penyebaran kuesioner melalui pos, email, atau internet. 
Penerimaan

Sistem

Informasi...

662
Selanjutnya, pengukuran data dilakukan dengan menggunakan skala ordinal (likert), yaitu skala ukur yang memiliki kategori dan juga memiliki urutan. Kategori disini adalah kategori pilihan jawaban yang disediakan oleh peneliti. Biasanya kategori tersebut menggunakan istilah Sangat tidak setuju (STS), Tidak setuju (TS), Netral (N), Setuju (S), dan Sangat setuju (SS). Untuk urut-urutannya sensiri adalah jika diurutkan dari sangat tidak setuju (STS) s/d Sangat setuju (SS). Sumber instrument penelitian ini sendiri mengadopsi penelitian Mulyani (2012) dengan sedikit modifikasi agar sesuai dengan konteks penelitian ini. Operasionalisasi variabel disajikan pada Tabel 1.

\begin{tabular}{|c|c|c|c|c|}
\hline No & Variabel & Indikator & Kuesioner & Kode \\
\hline \multirow[t]{4}{*}{1} & \multirow{4}{*}{$\begin{array}{l}\text { Desain } \\
\text { sistem } \\
\text { BLUD }\end{array}$} & Terminologi & $\begin{array}{l}\text { Singkatan yang digunakan dalam sistem } \\
\text { BLUD mudah dipahami }\end{array}$ & DSB1 \\
\hline & & \multirow{2}{*}{$\begin{array}{l}\text { Desain } \\
\text { antarmuka }\end{array}$} & $\begin{array}{l}\text { Sistem BLUD memiliki tamipilan yang } \\
\text { menarik dan tidak membosankan }\end{array}$ & DSB2 \\
\hline & & & $\begin{array}{l}\text { Informasi yang ditampilkan dalam BLUD } \\
\text { membantu saya dalam bekerja }\end{array}$ & DSB3 \\
\hline & & Navigasi & $\begin{array}{l}\text { Menu-menu dalam sistem BLUD } \\
\text { memudahkan saya dalam mengoperasikan } \\
\text { sistem BLUD }\end{array}$ & DSB4 \\
\hline \multirow[t]{5}{*}{2} & \multirow{5}{*}{$\begin{array}{l}\text { Sistem } \\
\text { informasi } \\
\text { akuntansi } \\
\text { (SIA) }\end{array}$} & \multirow{3}{*}{$\begin{array}{l}\text { Kualiats pengolah } \\
\text { data }\end{array}$} & $\begin{array}{l}\text { Pengolah data dalam sistem BLUD terkait } \\
\text { sistem informasi akuntansi mudah } \\
\text { digunakan }\end{array}$ & SIA1 \\
\hline & & & $\begin{array}{l}\text { Pengolah data dalam sistem BLUD } \\
\text { membantu saya dalam membuat laporan- } \\
\text { laporan yang diperlukan }\end{array}$ & SIA2 \\
\hline & & & $\begin{array}{l}\text { Pengolah data dalam sistem BLUD } \\
\text { membantu saya dalam membuat laporan } \\
\text { keuangan }\end{array}$ & SIA3 \\
\hline & & \multirow[b]{2}{*}{ Kualitas data } & $\begin{array}{l}\text { Informasi yang ada dalam sistem BLUD } \\
\text { dapat dengan mudah dipahami }\end{array}$ & SIA4 \\
\hline & & & $\begin{array}{l}\text { Informasi hasil pengolahan sistem BLUD } \\
\text { sangat bermanfaat untuk pengambilan } \\
\text { keputusan }\end{array}$ & SIA5 \\
\hline \multirow[t]{5}{*}{3} & \multirow[t]{5}{*}{$\begin{array}{l}\text { Users } \\
\text { abilities } \\
\text { and skills }\end{array}$} & \multirow{2}{*}{$\begin{array}{l}\text { Perkembangan } \\
\text { diri }\end{array}$} & $\begin{array}{l}\text { Saya memiliki kemampuan yang baik } \\
\text { dalam mengoperasikan komputer }\end{array}$ & UAS1 \\
\hline & & & $\begin{array}{l}\text { Saya dapat mengoperasikan sistem BLUD } \\
\text { dengan baik }\end{array}$ & UAS2 \\
\hline & & \multirow{2}{*}{ Pengalaman } & $\begin{array}{l}\text { Saya telah memiliki kemampuan dalam } \\
\text { menggunakan sistem BLUD setelah } \\
\text { beberapa kali menggunakannya }\end{array}$ & UAS3 \\
\hline & & & $\begin{array}{l}\text { Pengalaman saya dalam menggunakan } \\
\text { sistem memudahkan saya dalam } \\
\text { menggunakan sistem BLUD }\end{array}$ & UAS4 \\
\hline & & $\begin{array}{l}\text { Domain } \\
\text { knowledge }\end{array}$ & $\begin{array}{l}\text { Saya memiliki pengetahuan yang cukup } \\
\text { mengenai sistem BLUD }\end{array}$ & UAS5 \\
\hline \multirow[t]{5}{*}{4} & \multirow[t]{5}{*}{$\begin{array}{l}\text { Norma } \\
\text { subyektif }\end{array}$} & \multirow{4}{*}{$\begin{array}{l}\text { Pengaruh } \\
\text { interpersonal }\end{array}$} & $\begin{array}{l}\text { Saya berkeinginan untuk menggunakan } \\
\text { sistem BLUD atas saran atasan saya }\end{array}$ & SBN1 \\
\hline & & & $\begin{array}{l}\text { Saya termotivasi menggunakan sistem } \\
\text { BLUD seperti yang disarankan oleh teman } \\
\text { satu kantor saya }\end{array}$ & SBN2 \\
\hline & & & $\begin{array}{l}\text { Pendapat atasan saya memengaruhi saya } \\
\text { untuk menggunakan sistem BLUD }\end{array}$ & $\mathrm{SBN} 4$ \\
\hline & & & $\begin{array}{l}\text { Melihat teman-teman saya menggunakan } \\
\text { sistem BLUD mendorong saya untuk } \\
\text { menggunakan sistem BLUD }\end{array}$ & SBN5 \\
\hline & & $\begin{array}{l}\text { Pengaruh } \\
\text { eksternal }\end{array}$ & $\begin{array}{l}\text { Pendapat penyedia sistem BLUD } \\
\text { berpengaruh pada saya untuk } \\
\text { menggunakan sistem BLUD tersebut }\end{array}$ & SBN3 \\
\hline
\end{tabular}




\begin{tabular}{|c|c|c|c|c|}
\hline \multirow[t]{5}{*}{5} & \multirow[t]{5}{*}{$\begin{array}{l}\text { Percieved } \\
\text { usefulness }\end{array}$} & \multirow{4}{*}{$\begin{array}{l}\text { Peningkatan } \\
\text { efektivitas kerja }\end{array}$} & $\begin{array}{l}\text { Meggunakan sistem BLUD } \\
\text { memungkinkan untuk menyelesaikan } \\
\text { tugas saya lebih cepat }\end{array}$ & PU1 \\
\hline & & & $\begin{array}{l}\text { Menggunakan sistem BLUD dapat } \\
\text { meningkatkan kinerja saya }\end{array}$ & PU2 \\
\hline & & & $\begin{array}{l}\text { Menggunakan sistem BLUD dalam } \\
\text { pekerjaan saya dapat meningkatkan } \\
\text { produktivitas saya dalam bekerja }\end{array}$ & PU4 \\
\hline & & & $\begin{array}{l}\text { Menggunakan sistem BLUD dapat } \\
\text { meningkatkan efektivitas dalam bekerja }\end{array}$ & PU5 \\
\hline & & $\begin{array}{l}\text { Menyederhanakan } \\
\text { proses kerja }\end{array}$ & $\begin{array}{l}\text { Menggunakan sistem BLUD dapat } \\
\text { membuat pekerjaan saya lebih mudah } \\
\text { dilakukan }\end{array}$ & PU3 \\
\hline & & $\begin{array}{l}\text { Keseluruhan } \\
\text { sistem berguna }\end{array}$ & $\begin{array}{l}\text { Saya merasa sistem BLUD bermanfaat } \\
\text { dalam pekerjaan saya }\end{array}$ & PU6 \\
\hline \multirow[t]{6}{*}{6} & \multirow[t]{6}{*}{$\begin{array}{l}\text { Percieved } \\
\text { easeof use }\end{array}$} & \multirow{5}{*}{$\begin{array}{l}\text { Sistem mudah } \\
\text { digunakan }\end{array}$} & $\begin{array}{l}\text { Belajar menggunakan sistem BLUD itu } \\
\text { mudah bagi saya }\end{array}$ & PEOU1 \\
\hline & & & $\begin{array}{l}\text { Saya menemukan dengan mudah apa } \\
\text { yang saya butuhkan dari sistem BLUD }\end{array}$ & PEOU2 \\
\hline & & & $\begin{array}{l}\text { Interaksi saya dengan sistem BLUD jelas } \\
\text { dan dapat dimengerti }\end{array}$ & PEOU3 \\
\hline & & & $\begin{array}{l}\text { Saya merasa sistem BLUD fleksibel untuk } \\
\text { berinteraksi }\end{array}$ & PEOU4 \\
\hline & & & $\begin{array}{l}\text { Hal yang mudah bagi saya untuk terampil } \\
\text { dalam menggunakan sistem BLUD }\end{array}$ & PEOU5 \\
\hline & & $\begin{array}{l}\text { Keseluruhan } \\
\text { sistem mudah } \\
\text { digunakan } \\
\end{array}$ & $\begin{array}{l}\text { Saya merasa sistem BLUD mudah } \\
\text { digunakan }\end{array}$ & PEOU6 \\
\hline \multirow[t]{4}{*}{7} & \multirow[t]{4}{*}{$\begin{array}{l}\text { Attitude } \\
\text { toward } \\
\text { using }\end{array}$} & \multirow{2}{*}{ Kesenangan } & $\begin{array}{l}\text { Saya merasa senang berinteraksi dengan } \\
\text { sistem BLUD }\end{array}$ & ATU1 \\
\hline & & & $\begin{array}{l}\text { Menggunakan sistem BLUD memberikan } \\
\text { saya banyak kesenangan }\end{array}$ & ATU2 \\
\hline & & $\begin{array}{l}\text { Menikmati } \\
\text { penggunaan }\end{array}$ & $\begin{array}{l}\text { Saya menikmati menggunakan sistem } \\
\text { BLUD }\end{array}$ & ATU3 \\
\hline & & $\begin{array}{l}\text { Tidak } \\
\text { membosankan }\end{array}$ & $\begin{array}{l}\text { Menggunakan Sistem BLUD membuat } \\
\text { saya bosan }\end{array}$ & ATU4 \\
\hline \multirow[t]{5}{*}{8} & \multirow[t]{5}{*}{$\begin{array}{l}\text { Behavioral } \\
\text { intention to } \\
\text { use }\end{array}$} & \multirow{2}{*}{$\begin{array}{l}\text { Selalu mencoba } \\
\text { menggunakan }\end{array}$} & $\begin{array}{l}\text { Saya selalu mencoba menggunakan sistem } \\
\text { BLUD ketika sistem tersebut memiliki } \\
\text { fitur yang dapat membantu kinerja saya }\end{array}$ & BITU1 \\
\hline & & & $\begin{array}{l}\text { Saya selalu mencoba menggunakan sistem } \\
\text { BLUD pada banyak situasi/ kesempatan } \\
\text { yang memungkinkan }\end{array}$ & BITU2 \\
\hline & & \multirow{3}{*}{$\begin{array}{l}\text { Berlanjut dimasa } \\
\text { datang }\end{array}$} & $\begin{array}{l}\text { Saya berencana menggunakan sistem } \\
\text { BLUD suatu saat nanti }\end{array}$ & BITU3 \\
\hline & & & $\begin{array}{l}\text { Saya berniat untuk terus menggunakan } \\
\text { sistem BLUD suatu saat nanti }\end{array}$ & BITU4 \\
\hline & & & $\begin{array}{l}\text { Saya berharap untuk terus menggunakan } \\
\text { sistem BLUD suatu saat nanti }\end{array}$ & BITU5 \\
\hline \multirow[t]{5}{*}{9} & \multirow[t]{5}{*}{$\begin{array}{l}\text { Actual } \\
\text { system } \\
\text { usage }\end{array}$} & \multirow{3}{*}{$\begin{array}{l}\text { Frekuensi } \\
\text { penggunaan } \\
\text { sistem }\end{array}$} & $\begin{array}{l}\text { Saya mengakses sistem BLUD selama } \\
\text { hari-hari saya bekerja }\end{array}$ & ASU1 \\
\hline & & & $\begin{array}{l}\text { Setiap melakukan pekerjaan saya } \\
\text { menggunakan sistem BLUD } \\
\text { Saya mengakses sistem BLUD hampir } \\
\text { setiap hari }\end{array}$ & $\begin{array}{l}\text { ASU2 } \\
\text { ASU3 }\end{array}$ \\
\hline & & & $\begin{array}{l}\text { Saya mengakses sistem BLUD rata-rata } \\
\text { minimal } 10 \text { menit setap mengunjunginya }\end{array}$ & ASU4 \\
\hline & & \multirow{2}{*}{$\begin{array}{l}\text { Kepuasan } \\
\text { Penggunaa }\end{array}$} & $\begin{array}{l}\text { Secara keseluruhan saya merasa puas } \\
\text { dengan kinerja sistem BLUD }\end{array}$ & ASU5 \\
\hline & & & $\begin{array}{l}\text { Saya menyampaikan kepuasan terhadap } \\
\text { sistem BLUD kepada sesama teman kerja } \\
\text { di kantor }\end{array}$ & ASU6 \\
\hline
\end{tabular}




\section{Penerimaan \\ Sistem \\ Informasi...}

664

\section{Analisis data}

Teknik analisis data yang digunakan dalam penelitian ini adalah dengan menggunakan structural equation model (SEM). Dimana alat analisis yang digunakan adalah partial least square (PLS). SEM sendiri adalah alat analisis statistik yang digunakan untuk menyelesaikan model penelitian bertingkat secara serempak (Mulyani, 2012). Pengujian SEM ini dapat dilakukan dengan melihat diagram jalur (path)atau mlalui tabel path coefficient(Ghozali, 2014).

Arah pengujian hipotesis dapat diketahui dengan melihat tabel kolom original sample, jika menunjukan nilai positif maka hubungannya adalah positif, sedangkan jika nilainya menunjukan negatif maka hubungannya adalah negatif.Kemudian syarat selanjutnya adalah jika nilai t statistik lebih dari 1,64 untuk hipotesis -one-tiled (hipotesis berarah) atau 1,96 untuk hipotesis two-tiled (hipotesis tidak berarah) dan probability value ( $\mathrm{p}$-value) kurang dari 0,05 atau 5\%. Dimana ketiga syarat tersebut harus terpenuhi agar suatu hipotesis dapat dikatakan diterima.

\section{HASIL DAN PEMBAHASAN}

\section{Evaluasi Model Pengukuran (outer model)}

\section{Validitas Konvergen}

Evaluasi model pengukuran (outer model) ditujukan untuk menguji validitas dan reliabilitas data. Adapun dalam melakukan prosedur outer model adalah dengan melakukan pengujian validitas konstruk yang terdiri dari dari validitas konvergen dan validitas diskriminan, serta pengujian reliabilitas.

Berdasarkan output pada tabelouter loading ditemukan bahwa seluruh indikator dari setiap konstruk menujukan nilai $>0,60$. Bahkan hampir setiap indikator menunjukan nilai $>0,70$. Artinya bahwa seluruh indikator yang membentuk setiap konstruk dikatakan valid (Ghozali, 2014). Namun, sebelumnya pada pengujian awal validitas, ditemukan bahwa salah satu indikator pada konstruk sistem informasi akuntansi (SIA) tepatnya pada pernyataan (indikator) 1 tidak memenuhi rule of thumb atau nilainya $<0,60$. karenanya indikator tersebut dihapus agar setiap indikator memenuhi rule of thumb yang ditetapkan, yaitu >0,60.

Selanjutnya, nilai average variance extracted (AVE) ditemukan bahwa nilai AVE dari setiap konstruk menunjukan nilai $>0,50$. Dengan nilai terkecil adalah pada konstruk subjective norms (SBN) dengan nilai 0,593 dan nilai tersbesar adalah pada konstruk attitude toward using (ATU) sebesar 0,817. Artinya bahwa seluruh konstruk dapat dikatakan valid (Ghozali, 2014).

\section{Validitas Diskriminan}

Berdasarkan perbandingan antara tabel 2 dengan tabel 3 ditemukan bahwa nilai akar AVE lebih besar bila dibandingkan dengan nilai hubungan antar variabel. Sebagai contoh adalah nilai akar AVE pada konstruk ASU yaitu sebesar 0,850175 lebih besar bila dibandingkan dengan nilai hubungan antara ASU dengan ATU, BITU, DSB, PEOU, PU, SBN, SIA dan UAS yang ditunujukan pada tabel fornell-larcker. Hal tersebut menunjukan bahwa setiap variabel telah valid (Ghozali, 2014). 


\begin{tabular}{lcc}
\hline & AVE & Akar AVE \\
\hline ASU & 0,723 & 0,850175 \\
ATU & 0,817 & 0,903660 \\
BITU & 0,728 & 0,853344 \\
DSB & 0,657 & 0,810596 \\
PEOU & 0,704 & 0,838789 \\
PU & 0,801 & 0,895135 \\
SBN & 0,593 & 0,769822 \\
SIA & 0,745 & 0,863039 \\
UAS & 0,690 & 0,830795 \\
\hline
\end{tabular}

\begin{tabular}{llllllllll}
\hline & ASU & ATU & BITU & DSB & PEOU & PU & SBN & SIA & UAS \\
\hline ASU & 0,850 & & & & & & & & \\
ATU & 0,747 & 0,904 & & & & & & & \\
BITU & 0,701 & 0,668 & 0,853 & & & & & & \\
DSB & 0,523 & 0,547 & 0,663 & 0,811 & & & & & \\
PEOU & 0,761 & 0,703 & 0,686 & 0,565 & 0,839 & & & & \\
PU & 0,592 & 0,619 & 0,642 & 0,725 & 0,619 & 0,895 & & & \\
SBN & 0,498 & 0,393 & 0,433 & 0,383 & 0,346 & 0,439 & 0,770 & & \\
SIA & 0,592 & 0,601 & 0,741 & 0,861 & 0,482 & 0,795 & 0,403 & 0,863 & \\
UAS & 0,664 & 0,772 & 0,626 & 0,559 & 0,594 & 0,668 & 0,386 & 0,669 & 0,831 \\
\hline
\end{tabular}

Tabel 3.

Fornell-Larcker

\section{Reliabilitas}

Uji reliabilitas dilakukan untuk menguji kosistensi alat ukur dalam melakukan pengukuran (Abdillah dan Hartonoo, 2014). Untuk menguji reliabilitas setiap alat ukur yang digunakan dalam penelitian ini, peneliti menggunakan Cronbachs Alpha dan Composite Reliability. Nilai cronbachs alpha dari setiap konstruk menunjukan nilai $>0,70$, artinya bahwa setiap konstruk yang difunakan dalam penelitian ini dapat dikatakan reliabel (Ghozali, 2014). Sementara compsite reliability juga menunjukan nilai dari setiap konstruk $>0,70$, artinya bahwa setiap konstruk dalam penelitian ini reliabel (Ghozali, 2014).

\section{Evaluasi model struktural (inner model)}

Evaluasi Model Struktural atau inner model adalah ditujukan untuk memprediksi hubungan antara variabel laten, (Ghozali dan Latan, 2015). Menurut Hartono dan Abdillah (2014) untuk mengukur inner model dpat dilakukan dengan menggunakan $\mathrm{R}^{2}$ untuk konstruk yang dipengaruhi, serta koefisien path, atau nilai $t$-values setiap path untuk menguji signifikansi hubungan setiap konstruk. Adapun hasil dari evaluasi model struktural (inner model) dalam penelitian ini disajikan pada Tabel 4 .

\begin{tabular}{lc}
\hline & Original Sample (0) \\
\hline ASU & 0,476 \\
ATU & 0,521 \\
BITU & 0,500 \\
PEOU & 0,411 \\
PU & 0,687 \\
\hline
\end{tabular}

Tabel 4.

$R$ Square Adjusted 


\section{Penerimaan Sistem Informasi...}

666
Untuk melihat $\mathrm{R}^{2}$ adjusted dapat dilakukan dengan melihat nilai pada kolom original sample pada tabel 4.12. Nilai tersebut menunjukan seberapa besar pengaruh konstruk yang mempengaruhi terhadap konstruk yang dipengaruhi. Dari data pada tabel tersebut dapat diuraikan sebagai berikut:

1) Actual system usage (ASU). Konstruk actual system usage dipengaruhi oleh konstruk yang yang mempengaruhi yaitu konstruk behavioral intention to use (BITU) sebesar 0,476 atau 47,6\%. Selebihnya atau sebesar 52,4\% dipengaruhi oleh konstruk lain.

2) Attitude toward using (ATU). Konstruk attitude toward using dipengaruhi oleh konstruk yang mempengaruhinya yaitu konstruk percieved usefulness (PU) dan percieved ease of use (PEOU) sebesar 0,521 atau 52,1\%. Sedangkan pengaruh lain sebesar $47,9 \%$ dipengaruhi oleh konstruk lain diluar kedua kontruk tersebut.

3) Behavioral intention to use (BITU). Konstruk behavioral intention to use dipengaruhi oleh konstruk yang mempengaruhinya yaitu percieved usefulness, attitude toward using, dan subjective norm sebesar 0,500 atau sebesar 50\%. Sedangkan 50\% lainnya merupakan pengaruh dari variabel lain diluar ketiga konstruk tersebut.

4) Percieved ease of use (PEOU). Konstruk percieved ease of use dipengaruhi oleh konstruk yang mempengaruhinya yaitu desain sistem BLUD, sistem informasi akuntansi, dan users abilities and skills sebesar 0,411 atau sebesar 41,1\%. Sedangkan 58,9\% lainnya merupakan pengaruh dari variabel lain diluar ketiga konstruk tersebut.

5) Percieved usefulness (PU). Konstruk percieved usefulness dipengaruhi oleh konstruk yang mempengaruhinya sistem informasi akuntansisebesar 0,687 atau sebesar $68,7 \%$. Sedangkan $31,3 \%$ lainnya merupakan pengaruh dari variabel lain diluar dari konstruk tersebut.

\section{Hasil Uji Hipotesis}

Nilai original sample pada tabel path coefficient adalah positif yaitu sebesar 0,611 , artinya bahwa arah dari pengujian ini sesuai dengan hipotesis yang diajukan. Kemudian nilai $t$-statistics adalah sebesar 1,861 atau >1,64, namun nilai $p$-values menunjukan nilai sebesar 0,063 atau >0,05. Artinya bahwa bahwa salah satu kriteria tidak terpenuhi, jadi dapat disimpulkan bahwa $\mathrm{H} 1$ ditolak, maka desain sistem BLUD tidak berpengaruh terhadap percieved ease of use.Hasil yang tidak signifikan ini dapat terjadi karena masalah awal dari peneltian ini sendiri, yaitu masih sangat kurangnya tenaga yang ahli di bidang akuntansi dan keuangan yang ada pada Puskesmas BLUD, sehingga kemungkinan para pengguna sistem BLUD juga merangkap sebagai tenaga medis. Sehingga dampaknya adalah mereka tidak terlalu memperhatikan kemudahan yang didapat, mereka lebih mementingkan manfaat yang didapat dari sistem BLUD yang tujuannya untuk meningkatkan efisiensi dan efektifitas. Hal tersebut sesuai dengan teori keyakinan sendiri (self efficacy) yang membedakan pertimbangan diri sendiri (self efficacy) dan pertimbangan hasil (outcome). Hasil ini menunjukan bahwa ketika para pemakai sistem BLUD tidak dihadapkan pada pertimbangan hasil, maka mereka akan mempertimbangkan keyakinan mereka sendiri. Sehingga walaupun dengan desain sistem BLUD yang dibuat sedemikian rupa tidak mengubah persepsi para penggunanya bahwa sistem mudah digunakan. 


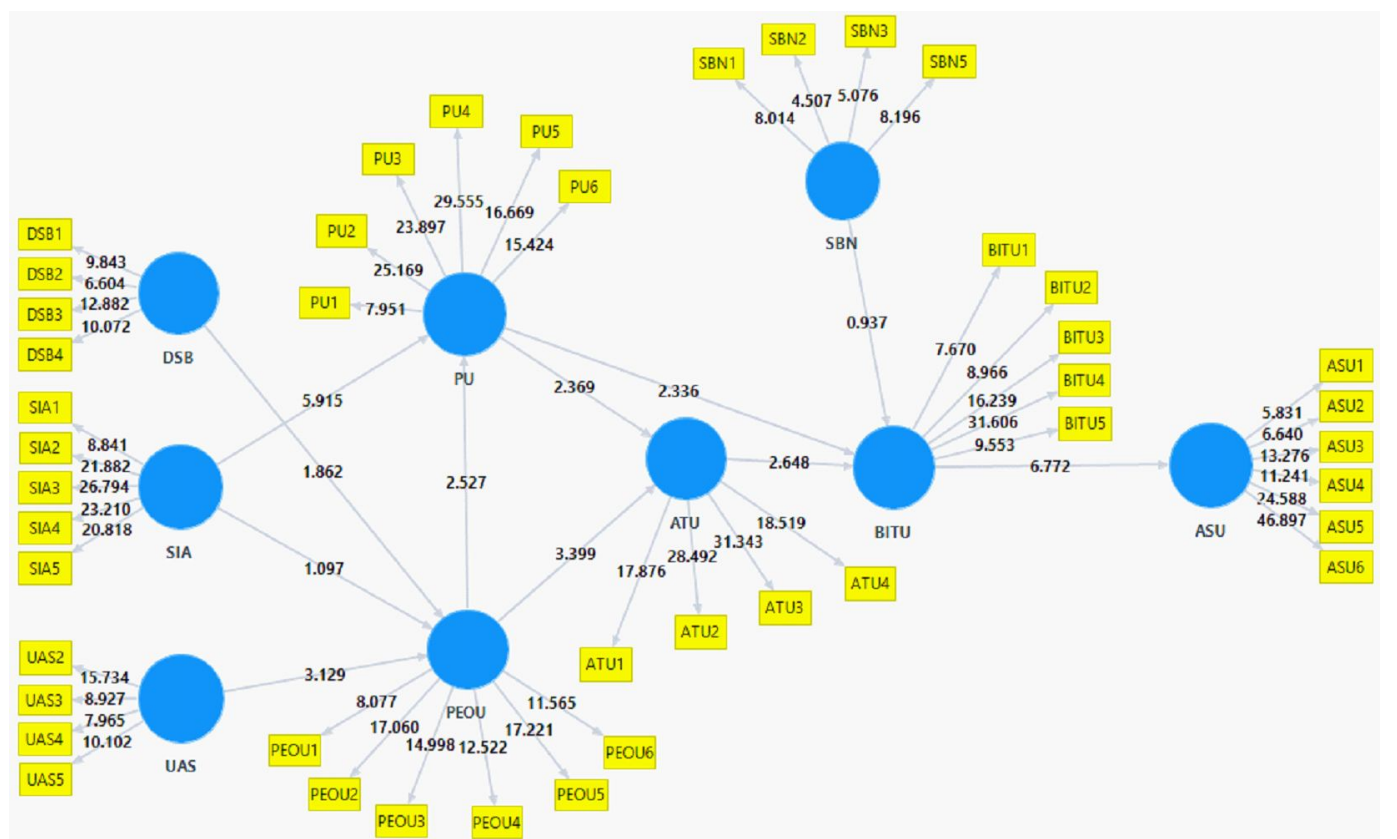

Dilihat dari tabel path coefficient menunjukan nilai original sample adalah negatif yaitu sebesar -0,384, artinya bahwa arah dari pengujian ini tidak sesuai dengan hipotesis yang diajukan. Kemudian nilai $t$-statistics adalah sebesar 1,126 atau $<1,64$, dengan nilai $p$-values sebesar 0,261 atau $>0,05$. Ketiga kriteria tidak terpenuhi, jadi dapat disimpulkan bahwa H2ditolak, maka sistem informasi akuntansi BLUD tidak berpengaruh terhadap percieved ease of use. Hasil ini diduga terjadi karena masalah kurangnya tenaga yang ahli di bidang akuntansi dan keuangan yang ada pada Puskesmas BLUD. Sehingga dampaknya adalah mereka tidak terlalu memperhatikan kemudahan dari sistem BLUD itu sendiri, mereka lebih mementingkan manfaat yang didapat dari sistem BLUD yang tujuannya untuk meningkatkan efisiensi dan efektifitas pekerjaan mereka.

Dilihat dari tabel menunjukan nilai original sample adalah positif yaitu sebesar 0,647, artinya bahwa arah dari pengujian ini sesuai dengan hipotesis yang diajukan. Kemudian nilai $t$-statistics adalah sebesar 5,918 atau $>1,64$, dengan nilai $p$-values sebesar 0,000 atau $<0,05$. Ketiga kriteria telah terpenuhi, jadi dapat disimpulkan bahwa H3 diterima, maka sistem informasi akuntansi BLUD berpengaruh positif terhadap percieved usefulness.Salah satu pertimbangan dalam teori keyakinan sendiri (self efficacy) yaitu pertimbangan hasil (outcome) bahwa perilaku seseorang dipengaruhi oleh hasil yang diperoleh jika seseorang tersebut melakukan sesuatu dan berhasil. Hasil ini membuktikan bahwa hasil (outcome) atau dalam hal ini manfaat yang diperoleh oleh pengguna sistem mempengaruhi persepsi dari pengguna sistem itu sendiri, yaitu bahwa sistem memberikan manfaat pada dirinya. Hasil penelitian ini memiliki makna bahwa semakin baik sistem informasi akuntansi yang ada dalam sistem BLUD, maka semakin tinggi persepsi pemakai sistem BLUD bahwa sistem BLUD memberikan manfaat bagi dirinya.

Dilihat dari tabel menunjukan nilai original sample adalah positif yaitu sebesar 0,509, artinya bahwa arah dari pengujian ini sesuai dengan hipotesis yang diajukan. Kemudian nilai $t$-statistics adalah sebesar 3,082 atau $>1,64$, dengan nilai $p$-values sebesar 0,002 atau $<0,05$. Ketiga kriteria telah terpenuhi, jadi dapat disimpulkan bahwa H4 diterima, maka users abilities and skills berpengaruh positif terhadap percieved ease of use.Hasil yang signifikian ini memiliki makna bahwa semakin baik kemampuan dan ketrampilan pengguna sistem BLUD maka semakin tinggi persepsi kemudahan penggunaan dari para penggunanya. Walau-
Gambar 2 .

Diagram Jalur (path) 
Penerimaan Sistem Informasi...

668 pun masalah dalam penelitian ini merupakan kemampuan para pengguna yang kebanyakan tidak memiliki keahlian khusus dibidang akuntansi dan keuangan, namun dengan pengalaman penggunaan sistem yang telah dilalui para pemakai sistem membuat kemampuan mereka meningkat. Selain itu dengan pengalaman tersebut juga mebuat para pengguna sistem BLUD lebih memahami sistem BLUD itu sendiri.

Dilihat dari tabel menunjukan nilai original sample adalah positif yaitu sebesar 0,308, artinya bahwa arah dari pengujian ini sesuai dengan hipotesis yang diajukan. Kemudian nilai $t$-statistics adalah sebesar 2,477 atau $>1,64$, dengan nilai $p$-values sebesar 0,014 atau $<0,05$. Ketiga kriteria telah terpenuhi, jadi dapat disimpulkan bahwa H5diterima, maka percieved ease of use berpengaruh positif terhadap percieved usefulness. Hasil yang positif signifikan ini menunjukan bahwa semakin baik persepsi kemudahan sistem BLUD oleh penggunanya, maka semakin tinggi pula persepsi kebermanfaatan dari sistem BLUD itu sendiri oleh penggunanya. Hasil tersebut sesuai dengan penelitian yang dilakukan oleh Wu dan Wang (2004), Lin et al. (2011), Mulyani (2012), dan Budiman dan Arza (2013) yang membuktikan bahwa konstruk percieved ease of use memiliki hubungan positif signifikan. Hasil tersebut juga menunjukan konsistensi dari model awal yang dikembangkan oleh Davis (1986) yang juga menemukan bahwa konstruk percieved ease of use memiliki pengaruh signifikan terhadap percieved usefulness.

Dilihat dari tabel menunjukan nilai original sample adalah positif yaitu sebesar 0,518, artinya bahwa arah dari pengujian ini sesuai dengan hipotesis yang diajukan. Kemudian nilai $t$-statistics adalah sebesar 3,296 atau $>1,64$, dengan nilai $p$-values sebesar 0,001 atau $<0,05$. Ketiga kriteria telah terpenuhi, jadi dapat disimpulkan bahwa $\mathrm{H} 6$ diterima, maka percieved ease of use berpengaruh positif terhadap attitude toward using.Hasil dalam penelitian ini membuktikan konsistensi dengan penelitian awal TAM yang dilakukan oleh Davis (1986). Artinya bahwa semakin baik persepsi pengguna sistem BLUD bahwa sistem mudah digunakan, maka semakin baik pula sikap yang tujukan oleh pengguna sistem BLUD tadi kearah menggunakan sistem tersebut. Atau kemudahan dalam menggunakan sistem BLUD akan mendorong sikap pengguna sistem BLUD kearah penggunaan sistem.

Dilihat dari tabel menunjukan nilai original sample adalah positif yaitu sebesar 0,299, artinya bahwa arah dari pengujian ini sesuai dengan hipotesis yang diajukan. Kemudian nilai $t$-statistics adalah sebesar 2,271 atau $>1,64$, dengan nilai $p$-values sebesar 0,024 atau $<0,05$. Ketiga kriteria telah terpenuhi, jadi dapat disimpulkan bahwa H7diterima, maka percieved usefulness berpengaruh positif terhadap attitude toward using.Dari teori perilaku mandatoryyang mengharuskan para pengguna untuk lebih sering berinteraksi dengan sistem BLUD lebih menegaskan bahwa manfaat yang diperoleh mejadi faktor yang berpengaruh terhadap sikap para pengguna kearah menggunakan sistem BLUD. Artinya bahwa semakin baik persepsi yang diberikan oleh pengguna sistem BLUD tentang manfaat yang diberikan oleh sistem tersebut, maka semakin baik atau positif sikap yang ditunjukan oleh pemakai sistem BLUD. Hal tersebut dapat terjadi karena diduga dengan manfaat yang diberikan oleh sistem BLUD akan meningkatkan kinerja para penggunanya, sehingga selain akan meningkatkan efisiensi dan efektifitas kerja, penilaian dari atasannyapun juga akan menjadi baik.

Dilihat dari tabel menunjukan nilai original sample adalah positif yaitu sebesar 0,330, artinya bahwa arah dari pengujian ini sesuai dengan hipotesis yang diajukan. Kemudian nilai $t$-statistics adalah sebesar 2,246 atau $>1,64$, dengan nilai $p$-values sebesar 0,025 atau $<0,05$. Ketiga kriteria telah terpenuhi, jadi dapat disimpulkan bahwa $\mathrm{H} 8$ diterima, maka percieved usefulness berpengaruh positif terhadap behavioral intention to use.Hasil dalam penelitian ini menunjukan bahwa konstruk perieved usefulness berpengaruh positif signifikan terhadap konatruk 
behavioral intention to use. Artinya adalah semakin tinggi persepsi pengguna sistem BLUD tentang manfaat yang diberikan, maka akan semakin tinggi pula minat atau niat dari pengguna tersebut untuk menggunakan sistem BLUD. Hasil ini sesuai dengan hasil penelitian yang diperoleh oleh Wu dan Wang (2004), Yuadi (2009), dan Mulyani (2012).

Dilihat dari tabel menunjukan nilai original sample adalah positif yaitu sebesar 0,125, artinya bahwa arah dari pengujian ini sesuai dengan hipotesis yang diajukan. Namun nilai t-statistics menunjukan nilai sebesar 0,943 atau $<1,64$, dengan nilai $p$-values sebesar 0,346 atau $>0,05$. Dari data tersebut menunjukan bahwa dua dari tiga kriteria tidak terpenuhi, jadi dapat disimpulkan bahwa H9 ditolak, maka subjective norm tidak berpengaruh terhadap behavioral intention to use.Didasari dengan teori keyakinan sendiri (self efficacy) tepatnya pada pertimbangan sendiri, hasil yang tidak signifikan dapat terjadi ketika seorang pengguna sistem dalam menggunakan sistemnya adalah karena keinginan sendiri. Namun, dalam penelitian ini yang menjadi dasar adalah perilaku mandatoryyang dalam penggunaan sistem adalah tuntutan dari atasan baik dalam lingkup Pueskesmas BLUD ataupun dari pemerintah yang tertuang dalam UU No 11 Tahun 2008 yang mengharuskan para pengguna sistem BLUD untuk menggunakan sistem tersebut. Kemudian, hasil yang tidak signifikan antara konstruk subjective norm terhadap behavioral intention to use dapat terjadi karena diduga para pengguna yang sudah terbiasa menggunakan sistem BLUD hampir disetiap hari kerja mereka tanpa adanya intruksi dan kontrol secara langsung dari atasannya. Selain itu, dugaan lain yang timbul adalah karena manfaat yang diberikan dari sistem BLUD yang meringankan beban kerja para penggunanya, sehingga para pengguna sistem BLUD akan tetap menggunakan sistem tersebut entah itu dibawah tuntutan dari atasan ataupun tidak.

Dilihat dari tabel menunjukan nilai original sample adalah positif yaitu sebesar 0,415 , artinya bahwa arah dari pengujian ini sesuai dengan hipotesis yang diajukan. Kemudian nilai $t$-statistics adalah sebesar 2,743 atau $>1,64$, dengan nilai $p$-values sebesar 0,006 atau $<0,05$. Ketiga kriteria telah terpenuhi, jadi dapat disimpulkan bahwa H10 diterima, maka attitude toward using berpengaruh positif terhadap behavioral intention to use.Hasil penelitian ini memiliki makna bahwa semakin baik atau positif sikap yang ditunjukan oleh para pengguna sistem BLUD, maka akan semakin tinggi minat dari para pengguna tersebut untuk menggunakan sistem BLUD. Artinya, sikap positif yang ditujukan oleh peogguna sistem BLUD akan memberikan indikasi bahwa pengguna tersebut memiliki minat untuk menggunakan sistem BLUD.

Dilihat dari tabel menunjukan nilai original sample adalah positif yaitu sebesar 0,701 , artinya bahwa arah dari pengujian ini sesuai dengan hipotesis yang diajukan. Kemudian nilai $t$-statistics adalah sebesar 6,779 atau $>1,64$, dengan nilai $p$-values sebesar 0,000 atau $<0,05$. Ketiga kriteria telah terpenuhi, jadi dapat disimpulkan bahwa H11 diterima, maka behavioral intention to use berpengaruh positif terhadap actual system usage.Hasil ini sejalan dengan penelitian yang dilakukan oleh Mulyani (2012) dan Yuadi (2009) dimana konstruk minat memiliki pengaruh positif signifikan terhadap penggunaan nyata sistem. Bahkan dalam penelitian ini menunjukan bahwa hubungan antara minat dan penggunaan nyata sistem BLUD sebagai salah satu hubungan yang paling kuat, hal ini sejalan dengan penejelasan Hartono (2007) yang menjelaskan bahwa hubungan antara minat perilaku terhadap perilaku memiliki korelasi yang paling kuat bila dibandingkan dengan faktor-faktor lain. Hasil tersebut juga bermakna bahwa semakin tinggi niat atau minat pengguna sistem BLUD untuk menggunakan sistem tersebut, maka realisasi penggunaan nyata sistem BLUD juga akan semakin tinggi. Atau dengan kata lain semakin pasti para penggunanya akan menggunakan sistem BLUD. 


\section{Penerimaan Sistem Informasi...}

\section{SIMPULAN}

Penelitian ini bertujuan untuk menganalisis penerimaan sistem informasi akuntansi BLUD yang digunakan pada Puskesmas yang berstatus BLUD dengan menggunakan pendekatan technology acceptance model (TAM). Selain konstruk TAM yang digunakan untuk menganalisis penerimaan sistem informasi akuntansi BLUD, beberapa konstruk lain juga ditambahkan sebagai variabel anteseden untuk dapat menjelaskan beberapa konstruk TAM.

Hasil penelitian ini menunjukan bahwa users abilities and skills (UAS) terhadap percieved ease of use (PEOU), sistem informasi akuntansi (SIA) terhadap percieved usefulness (PU), percieved ease of use (PEOU) terhadap percieved usefulness (PU), percieved ease of use (PEOU)dan percieved usefulness (PU)terhadap attitude toward using (ATU), percieved usefulness (PU) dan attitude toward using (ATU) terhadap behavioral intention to use (BITU), dan behavioral intention to use (BITU) terhadap actual system usage (ASU) menunjuka hubungan positif signifikan. Sedangkan konstruk desain sistem BLUD (DSB) terhadap percieved ease of use (PEOU), sistem informasi akuntansi (SIA) terhadap percieved ease of use (PEOU), dan subjective norm (SBN) terhadap behavioral intention to use (BITU) tidak memiliki hubungan yang signifikan.

Selain itu penelitian ini juga menunjukan bahwa konstruk percieved usefulness (PU) memliki hubungan paling signifikan dengan beberapa variabel anteseden. Artinya bahwa, penyedia sistem BLUD diharapkan lebih meningkatkan manfaat yang diberikan dari sistem BLUD itu sendiri karena para pengguna lebih mementingkan manfaat yang diterima daripada kemudahan sistem yang diberikan.

Penelitian ini memiliki beberapa keterbatasan yang seyogyanya dapat diperbaiki di penelitian mendatang, yakni: pertama, penelitian ini menggunakan sampel yang masih sangat kecil, yakni puskesmas-puskesmas yang ada di kabupaten Boyolali. Karenanya, kekuatan generalisasi dari hasil penelitian ini masih sangat lemah. Penelitian mendatang diharapkan menambah sampel penelitian di lokasi yang berbeda-beda agar hasil yang diperoleh dapat membangun validitas eksternal atau tingkat generalisasi yang lebih kuat.Kedua, penelitian ini tidak mempertimbangkan lama waktu sampel dalam menggunakan SIA BLUD. Bisa jadi antara responden satu dan yang lain memiliki gap penggunaan SIA BLUD yang jauh berbeda, yang notabene tidak dieksplor secara lebih jauh pada penelitian ini. Oleh karena itu, penelitian selanjutnya diharapkan dapat mengeksplor lama waktu para responden telah menggunakan SIA BLUD agar temuan penelitian dapat lebih kritis menggali fenomena keberterimaan SIA di BLUD. Hal ini juga bertujuan agar dapat diperkirakan seberapa baik para responden memiliki pemahaman terhadap sistem yang dipakai.

Terakhir, rendahnya tingkat pengembalian kuesioner dikarenakan penyebaran kuesioner dilakukan di awal tahun, dimana pada waktu ini tim keuangan di puskesmas sedang sangat sibuk. Kondisi ini tidak menutup kemungkinan memunculkan bias tidak merespon kuesioner dengan baik. Karenanya, penelitian selanjutnya diharapakan penyebaran kuesioner dilakukan bukan pada awal tahun karena para pemakai umumnya sibuk dalam menyusun laporan keuangan, sehingga tingkat pengembalian keusioner menjadi lebih tinggi dan dapat terhindar dari kemungkinan adanya bias tidak merespon kuesiner dengan baik.

\section{DAFTAR PUSTAKA}

Budiman, F., dan Arza, F.I. 2013. "Pendekatan Technology Acceptance Model dalam Kesuksesan Implementasi Sistem Informasi Manajamen Daerah”. Jurnal WRA, Vol. 1, No. 1 April 2013. 
Cianjurekspres online. 2016. "Puskesmas BLUD Minim Tenaga Ahli Keuangan".

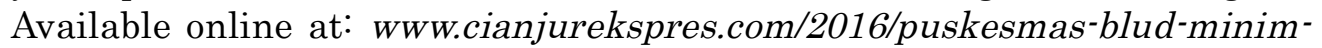
tenaga-ahli-keuangan/. (diakses pada 15 Desember 2016).

Chin, W. And Todd, P. 1995. "On The Use, Usefulness, And Ease Of Use Of Structural Equation Modeling In Mis Research: A Note Of Caution". Management Information System Quarterly 9, 2, Pp. 237-246.

Devi, N. L. N. S., dan Suartana, I. W. 2014. "Analisis Technology Acceptance Model (TAM) terhadap Penggunaan Sistem Informasi di Nusa Dua Beach Hotel dan Spa”. E-Jurnal Akuntansi, Vol 6. No. 1, pp 167-184.

Dalimunthe, N., dan Wibisono, H. 2014. "Analisis Penerimaan Sistem E-Learning SMK Labor Pekanbaru dengan Menggunakan Technology Acceptance Model (TAM)". Jurnal Sains dan Teknologi Industri, Vol.11 No.1, pp 111-117.

Davis, F.D,Jr 1986. A Technology Acceptance Model for Empirically Testing New End-User Information Systems: Theory and Results. Submitted to the Sloan School of Management, M.I.T. on December 20, 1985.

Davis, F.D. 1989. "Perceived Usefulness, Perceived Ease Of Use, And User Acceptance Of Information Technology". Management Information System Quarterly 13(3), Pp 319-340.

Doll, W.J., dan Torkzadeh, G.1998. "The Measurement of End-User Computing Satisfaction". Management Information System Quarterly 12(2), pp. 259-274.

Ghozali, I.2014. Aplikasi Structural Equation Modeling, Metode Alternatif dengan Partial Least Square (PLS), Edisi Pertama. Badan Penerbit Universitas Diponegoro. Semarang.

Ghozali, I. dan Latan. 2015. Patrial Least Square (Konsep, Tehnik, dan Aplikasi) Menggunakan program SmartPLS 3.0. Penerbit Universitas Diponegoro. Semarang.

Fatmawati, E. 2015. "Technology Acceptance Model (TAM) untuk Menganalisis Penerimaan Terhadap Sistem Informasi Perpustakaan”. Jurnal Iqra’ Vol. 9 No.01.

Indrayathi, P.A., Listyowati, R., Nopiyani, N.M.S., dan Ulandari, L.P.S. 2014. "Mutu Pelayanan Puskesmas Perawatan yang BerstatusBadan Layanan Umum Daerah”. Jurnal Kesehatan Masyarakat Nasional Vol. 9, No. 2.

Hartono, J. 2007. Sistem Informasi Keperilakuan. Edisis Revisi. Andi Offset. Yogyakarta.

Hartono, J dan Abdillah, W. 2014. Sistem Tata kelola Teknologi Informasi. Andi Offset, Yogyakarta.

Hendrawati, Tuty. 2013. "Analisis Penerimaan Sistem Informasi Integrated Library System (INLIS): Studi Kasus di Perpustakaan Nasional RI”. Visi Pustaka Vol. 15 No.3.

Lin, F., Fofanah, S.S., dan Liang, D. 2011. "Assessing Citizen Adoption of E-Gov" ernment Initiatives in Gambia: A Validation of The Technology Acceptance Model in Information Systems Success". Government Information Quarterly Vol. 28, pp 271-279.

Mulyani, A., dan Kurniadi, Dede. 2012. "Analisis Penerimaan Teknologi Student Information Terminal (S-IT) dengan Menggunakan Technology Acceptance Model (TAM)". Jurnal Wawasan Ilmiah, Vol. 2 No. 15.

Nah, Fui Hoon., Tan Xin., dan The Soon Hing. 2004. "An Empirical Investigation On End-Users' Acceptance Of Enterprise Systems".Information Resources Management Journal, Vol. 17

Peraturan Pemerintah Republik IndonesiaNomor 23 Tahun 2005 Tentang Pengelolaan Keuangan Badan Layanan Umum

Saadé, R., dan Bahli, B. 2005. "The Impact of Cognitive Absorption on Perceived Usefulness and Perceived Ease of Use in Online Learning: An Extension of 
Penerimaan

Sistem

Informasi...

672
The Technology Acceptance Model". Information dan Management Journal, Vol 42 No. 2, pp 317-327.

Surianto, dan Trisnantoro, L. 2013. "Evaluasi Penerapan Kebijakan Badan Layanan Umum Daerah di RSUD Undata Propinsi Sulawesi Tengah”. Jurnal Kebijakan Kesehatan Indonesia, Vol. 02, No. 1.

Syahril. 2013."Pola Pengelolaan Keuangan Badan Layanan Umum Daerah (PPKBLUD) pada RSUD DR. H. Moh. Anwar Sumenep". Jurnal "PERFORMANCE" Bisnis \& Akuntansi Volume III, No.1

Vijayasarathy, L. R. 2004. "Predicting Consumer Intentions to Use On-Line Shopping: The Case for An Augmented Technology Acceptance Model”. Information dan Management Journal, Vol. 41 No. 6, pp 747-762.

Wu, J.H., dan Wang, S.C. 2004. "What Drives Mobile Commerce? An Empirical Evaluation of The Revised Technology Acceptance Model". Information \& Management Journal, Vol. 42, pp 719-729.

Yuadi, I. 2009. "Analisis Technology Acceptance Model terhadapPerpustakaan Digital dengan Structural Equation Modeling”. Departemen Ilmu Informasi dan Perpustakaan. 
